\title{
Examining the Use of Thematic Analysis as a Tool for Informing Design of New Family Communication Technologies
}

\author{
Nela Brown \\ Queen Mary University of London \\ School of EECS \\ Peter Landin Building \\ 10 Godward Square \\ London E1 4FZ, UK \\ nelabrown@eecs.qmul.ac.uk
}

\author{
Tony Stockman \\ Queen Mary University of London \\ School of EECS \\ Peter Landin Building \\ 10 Godward Square \\ London E1 4FZ, UK \\ tony.stockman@eecs.qmul.ac.uk
}

\begin{abstract}
Frequently family members are geographically separated for large parts of the day. This separation, allied to a busy schedule, can make it difficult to share daily experiences and maintain the feeling of connectedness. This paper describes an exploratory study to investigate family dynamics and the use of technology in families with primary school children. We interviewed five families about their daily communication and use of technology. We examined the use of thematic analysis, a method for qualitative data analysis used in social science, as a tool for systematically identifying and describing features of qualitative data and informing the design of new family technologies. The results of the investigation showed that the first 3 phases of the 6-phase thematic analysis approach were the most fruitful in yielding information about the families' use of technology and information at a level that could be of value for designing new communications technology. The use of the full 6 phases of the approach however, is more appropriate where it is required to produce a summary of the data in a form of a high level thematic map accompanied by the analytic narrative.
\end{abstract}

Family dynamics. Communication. Technology. Semi-structured interviews. Thematic analysis.

\section{INTRODUCTION}

Parents with primary school children juggle work commitments and childcare with children's education and after-school activities on a daily basis. During the week, family members use calendars to schedule time spent apart, rather than time spent together, employing different tactics and available technology to keep in touch (Brown and Stockman, 2011).

The aim of this exploratory research is to investigate the general dynamics in families with primary school children, the experiences communicated between family members, the types of devices used to bridge the lack of contact and the perceived or actual limitations of the devices employed.

We conducted semi-structured interviews with five families and explored the usefulness of thematic analysis, a qualitative data analysis method used in social science. We aimed to explore the value of thematic analysis in analysing communications and the use of technology between family members, as well as its potential role in informing the design of new communications technologies for use by families.

\section{BACKGROUND}

\subsection{Qualitative methods}

According to Braun and Clarke (2006), methods of qualitative data analysis fall into two groups. The first group consists of methods driven by an epistemological or theoretical position, which have limited variability in how they are applied within their frameworks, such as conversation analysis (CA) and interpretative phenomenological analysis (IPA) and methods which are situated within a broad theoretical framework and can therefore be used in a variety of ways within those frameworks, such as grounded theory, discourse analysis (DA) and narrative analysis.

The second group includes methods independent of theory and epistemology, which can be applied across a range of different theoretical and 
epistemological approaches and are therefore very flexible.

One such method is thematic analysis, which through its theoretical freedom "provides a flexible and useful research tool, which can potentially provide a rich and detailed, yet complex account of data" (Braun and Clarke, 2006, p. 78).

\subsection{Use of thematic analysis in $\mathrm{HCl}$}

A number of recent $\mathrm{HCl}$ studies reported the use of thematic analysis to: analyse video recordings and interviews based on participants' use of technology prototypes (Pykhtina et al., 2012); gain a better understanding of users' experiences with existing technology, identify key interaction challenges and use this information to define functionality and usability requirements for a prototype of the improved technology (Money et al. (2008); identify themes across the dataset obtained through an online survey and use them to inform the design of an interactive system (Tanaka et al., 2012); analyse diaries and focus groups data to gain insight into users behaviour and use this to inform development of new mobile solutions (Toth et al., 2012); analyse images taken by the participants with a new mobile application as well as participants responses to those images and identify the usage patterns and benefits of using the application (Güldenpfennig, Reitberger and Fitzpatrick, 2012). The age of participants in these studies varied from young children (4-11) and teenagers to adults and elderly, with thematic analysis being used on all datasets apart from the ones gathered with the young children. Some of the studies (Pykhtina et al., 2012) did not include any details about their coding processes, some (Money et al., 2008) reported following the method as outlined in Joffe and Yardley (2004), whilst others (Güldenpfennig, Reitberger and Fitzpatrick, 2012; Tanaka et al., 2012; Toth et al., 2012) reported using the method as outlined in Braun and Clarke (2006). All of the studies reported the usefulness of thematic analysis as a tool for either evaluating existing technologies or informing the design of new technologies. Apart from Money et al. (2008), who formulated their findings into a thematic mind map, adapted from a thematic map (Braun and Clarke, 2006), all the other studies reported findings through identified themes or categories, using narrative underpinned with relevant data extracts. Güldenpfennig, Reitberger and Fitzpatrick (2012) also reported calculating inter-rater reliability, an important step for validating any qualitative method according to Boyatzis (1998).

We examined the two ways of conducting thematic analysis referenced in these studies, both of which came from the field of psychology (Joffe and Yardley, 2004; Braun and Clarke, 2006), as well as some other approaches from different fields
(Boyatzis, 1998; Fereday, and Muir-Cochrane, 2006). We decided to use the method outlined in Braun and Clarke (2006) as the guidelines for completion of analysis through a 6-phase approach were clear and easy to follow. Whilst the method itself was drawn from the field of psychology and $\mathrm{HCl}$ has greatly benefitted from the adoption of many techniques from psychology as well as other disciplines, we could not predict how the method would work when applied in the specific context of investigating family communication or how it might need to be tailored for the use in $\mathrm{HCl}$ contexts as a tool for informing design of new technologies.

\subsection{The six phases of thematic analysis}

The thematic analysis method outlined in Braun and Clarke (2006) consists of the following six phases:

- Phase 1: Familiarising yourself with the data by reading the whole data set and noting down initial ideas.

- Phase 2: Generating initial codes, with codes being the most basic segment of the raw data that can identify a feature of the data that appears interesting.

- Phase 3: Searching for themes by sorting different codes into potential themes and collating all data extracts within identified themes.

- Phase 4: Reviewing themes and refining them further (at the level of coded data extracts, and the entire data set) and producing a thematic map showing relationships between themes and subthemes.

- Phase 5: Defining and naming themes, making sure they give the reader immediate sense of what the theme is about.

- Phase 6: Producing a report to convince the reader of the merit and validity of the analysis (within and across themes), using data extracts embedded within an analytic narrative to make an argument in relation to the research question.

\section{THE STUDY}

\subsection{Participants}

We recruited five families with children of primary school age (5-11) through word of mouth from the suburbs of London (UK). Three of the families had younger children (aged 2, 3 and 4) and older children (aged 12 and 14) who also participated in the study. Two of the families had children who moved out of the family home (aged 18 and 29), who did not directly participate in the study but were referred to in the interviews, and this data was 
included in the coding process. The breakdown of participants including their code, gender and age is listed in Table 1.

Table 1: Participants: code, gender and age

\begin{tabular}{|c|c|c|c|}
\hline Family & Code & Gender & Age \\
\hline \multirow[t]{4}{*}{ Family 1} & M1 & $F$ & 48 \\
\hline & $D 1$ & $M$ & 51 \\
\hline & C1G8 & $F$ & 8 \\
\hline & C1G11 & $F$ & 11 \\
\hline Did not participate & C1B29 & $M$ & 29 \\
\hline \multirow[t]{4}{*}{ Family 2} & M2 & $F$ & 47 \\
\hline & $D 2$ & $M$ & 52 \\
\hline & C2G6 & $F$ & 6 \\
\hline & C2G12 & $F$ & 12 \\
\hline \multirow[t]{5}{*}{ Family 3} & M3 & $F$ & 45 \\
\hline & D3 & $M$ & 50 \\
\hline & C3B3 & $M$ & 3 \\
\hline & C3G8 & $F$ & 8 \\
\hline & C3G14 & $F$ & 14 \\
\hline Did not participate & C3G18 & $F$ & 18 \\
\hline \multirow[t]{6}{*}{ Family 4} & M4 & $F$ & 41 \\
\hline & $D 4$ & $M$ & 41 \\
\hline & $C 4 B 2$ & $M$ & 2 \\
\hline & C4B4 & $M$ & 4 \\
\hline & $C 4 B 6$ & $M$ & 6 \\
\hline & $C 4 B 8$ & $M$ & 8 \\
\hline \multirow[t]{4}{*}{ Family 5} & M5 & $F$ & 42 \\
\hline & $D 5$ & $M$ & 40 \\
\hline & C5G5 & $F$ & 5 \\
\hline & C5B10 & $M$ & 10 \\
\hline \multicolumn{4}{|c|}{$\begin{array}{l}\text { Total Family members: } 25 \\
\text { Total Participants: } 23\end{array}$} \\
\hline
\end{tabular}

\subsection{Data collection}

Semi-structured contextual interviews, labelled Introductory Interviews, aimed primarily at the parents, were conducted in the family home, though occasionally children were brought in by the parents to answer questions. Interviews were conducted by the principal investigator and consisted of a short introduction to the investigator's background and purpose of the study, followed by the signing of the consent forms. This was followed by a series of questions about daily family dynamics and the use of technology. On some occasions the use of technology was described in relation to the children who were no longer living at home, either when they were younger or at the present time. The interviews lasted between 50 to 100 minutes. They were audio recorded and transcribed. We used a 'verbatim' account of all verbal and sometimes nonverbal utterances (most of which were laughter), with the aim to produce a transcript that retains the nature of the original dialogue, but also suits the purpose of the analysis i.e. to find out about the use of communications technology by the families (Edwards, 1993). As we were usually interviewing more than one person, there were numerous occasions when parents would either be talking on behalf of each other or on behalf of their children, so we developed a coding system to distinguish the primary source of data (person being interviewed) and secondary source of data (person being referred to in the interview, regardless of whether they were present or absent). We trusted the parents to know each other well and know their children well, but still did not want to presume that they understood the motivations behind another family member's use of technology in one way or another. We coded the parents with M1 (mom, family one), D1 (dad, family one) and the children with C1G8 (child family 1, girl aged 8) in order to track who said what or responded to which question over the course of the interview when the extracts were collated.

Transcribing one hour of audio interview this way took around 16 hours. The interviews lasted 72 minutes with Family 1, 55 minutes with Family 2, 48 minutes with Family 3, 102 minutes with Family 4 and 55 minutes with Family 5 . A total of 5 hours and 32 minutes needed to be transcribed, which took around 88 hours and 40 minutes to complete using a word processor.

\subsection{Coding using thematic analysis}

We based the interview questions on our research questions about the general family dynamics and the current use of technology within families with primary school children. We followed an essentialist, inductive, data-driven approach identifying the themes on a semantic level. In Phase 1, we read each family data set several times before commencing coding. In Phase 2, we coded each speaker turn with a phrase that captured the meaning, sometimes using more than one code, as shown in Table 2.

Table 2: Example of initial coding, Family 2

\begin{tabular}{|c|c|}
\hline Transcription & Initial Codes (Phase 2) \\
\hline $\begin{array}{l}\text { D2: I'm like that, cause I } \\
\text { think most I miss about it } \\
\text { is the actual podcasts } \\
\text { and things when I go off } \\
\text { with the train that's it } \\
\text { mostly ... I miss about it } \\
\text { and radio uhm ... but } \\
\text { when I'm not with } \\
\text { anybody when you're on } \\
\text { the train cause it's } \\
\text { horrible pile of people on } \\
\text { the train it's uhh and } \\
\text { they've got their } \\
\text { earphones on really } \\
\text { really loudly but I just it's } \\
\text { sad [?] you miss there } \\
\text { when you don't want } \\
\text { communication but when } \\
\text { you're in the house it's } \\
\text { not good ... }\end{array}$ & $\begin{array}{l}\text { D2: mostly missing not } \\
\text { having iPhone to listen to } \\
\text { podcasts on the train } \\
\text { D2: missing listening to } \\
\text { radio when alone on train } \\
\text { D2: train horrible pile of } \\
\text { people } \\
\text { D2: train passengers } \\
\text { have earphones really } \\
\text { loud } \\
\text { D2: miss having iPhone } \\
\text { when doesn't want to } \\
\text { communicate } \\
\text { D2: iPhone not good } \\
\text { when you're in the house } \\
\text { (want to communicate) }\end{array}$ \\
\hline
\end{tabular}


This generated an extensive list of initial codes for each of the families: 214 for Family 1, 351 for Family 2, 113 for Family 3, 446 for Family 4 and 206 for Family 5 . The initial codes were very descriptive and low level, and produced a total of 154 initial themes for Family 1 in the Phase 3 of the coding process. During this phase some of the initial codes become the initial themes. In Phase 4, we grouped these initial themes into 37 higher-level themes. Our aim was to refine these 37 higherlevel themes further and produce a thematic map similar to the 'final thematic map' Braun and Clarke (2006, p.91) used as an example in their publication frequently cited by researchers using thematic analysis in $\mathrm{HCl}$, consisting of two main themes and six sub-themes (three per each theme).

\section{DISCUSSION OF FINDINGS}

After the first iteration in Phase 4, it became apparent that grouping themes into higher-level categories and thematic maps, whilst useful for representing a general overview of the data in social science studies, was less useful in our study, the purpose of which was to gain insights into participants' behaviour and the use of technology, than utilize these insights to either improve functionality and usability of the existing technologies or inform the design of new technologies. Example of differences between the initial themes in Phase 3, containing design level information and refined themes in Phase 4, containing more general information is shown in Table 3.

Table 3: Example of Phase 3 and Phase 4 themes

\begin{tabular}{|c|c|}
\hline $\begin{array}{c}\text { Initial Themes } \\
\text { (Phase 3) }\end{array}$ & $\begin{array}{c}\text { Refined Themes } \\
\text { (Phase 4) }\end{array}$ \\
\hline $\begin{array}{l}\text { C1G8 and C1G11 attended } \\
\text { primary school }\end{array}$ & School level \\
\hline $\begin{array}{l}\text { C1G8 walks to school or uses } \\
\text { a scooter accompanied by } M 1\end{array}$ & \multirow[t]{5}{*}{ Going to school } \\
\hline $\begin{array}{l}\text { C1G11 cycles to school } \\
\text { (school has a bike shelter) or } \\
\text { walks to school on her own }\end{array}$ & \\
\hline $\begin{array}{l}\text { C1G11 gets picked up from } \\
\text { school by M1 or D2 } 4 \text { days per } \\
\text { week }\end{array}$ & \\
\hline $\begin{array}{l}\text { C1G11 walks back from } \\
\text { school with a friend } 1 \text { day per } \\
\text { week }\end{array}$ & \\
\hline $\begin{array}{l}\text { M1 thinks C1G11 likes the } \\
\text { independence of going to } \\
\text { school on her own }\end{array}$ & \\
\hline $\begin{array}{l}\text { M1 worries about C1G11 } \\
\text { arriving to school safely }\end{array}$ & \multirow[t]{2}{*}{ Children's safety } \\
\hline $\begin{array}{l}\text { M1 checks C1G11 coat is on } \\
\text { the peg }\end{array}$ & \\
\hline
\end{tabular}

Table 3 clearly demonstrates that proceeding with the process of further iterations would have produced a thematic map that is too high-level and too general at the end of Phase 4. Further defining and naming the themes in Phase 5 would have made them even more abstract and removed from the useful (low-level) insights of Phase 3, which is why we decided to use the results of Phase 3 to inform our further research.

\section{CONCLUSIONS AND FURTHER WORK}

The 154 themes resulting from the coding of Family 1 in Phase 3 will serve as the starting point for the rest of our analysis. As we already generated initial codes, when completing Phase 2 with the other families, in Phase 3 , these initial codes will be matched to the already existing 154 themes. The codes that do not fit into those themes will form new themes, whilst some of the existing themes might be renamed to better capture the meaning of the codes and the data extracts on which they are based. When this phase is completed we will conduct inter-rater reliability tests with two independent researchers, resolve any differences in opinion and calculate the percentage of agreement. As the end result, we are aiming to have a detailed account of the family dynamics and the use of technology within families with primary school children in a form of a thematic frame. This thematic frame will contain a list of low-level themes captured across all five families, which could further be used to support researchers studying the use of technology within families in three different ways:

(i) Faster Coding: having a pre-existing list of themes (thematic frame) would enable faster coding of the new data gathered with families with primary school children (as well as outside of this range). It would also enable researchers to extend this list of themes with the addition of new themes based on the insights from their own research.

(ii) Solving Usability Issues: having a thematic frame, with a list of detailed insights into family members' behaviour with existing technologies, would enable researchers to ask different questions of the data, combine themes to solve usability issues and enhance the user experience through improved design of these technologies.

(iii) Design Innovation: having a thematic frame would enable researchers to look at the detailed insights regarding the everyday behaviour of the family members and combine themes to inform the design of novel technologies, addressing the issues not currently supported by the existing technologies. 
Whilst using just the first 3 phases of the 6-phase method outlined in Braun and Clarke (2006) might save researchers a significant amount of time when coding the data, matching initial codes to the existing list of themes should be exercised with great care to make sure that any subtle differences between the existing themes and initial codes of the new research are not lost in the process.

An example of the use of the thematic frame for Design Innovation can be found in Table 3. From just a few themes, we can conclude that out of the two primary school age children who are part of Family 1, the mother worries about the safety of her older (11 year old) daughter, as she walks to school by herself in the morning. We also know that she sometimes uses her bike as the school has a bike shelter and that her mother checks her coat is on the peg when she drops off the younger (8 year old) daughter to school.

A possible solution to alleviate some of the mother's anxiety (especially on the days she is not able to check the coat on the peg), would be to install sensors on the bike shelter and the coat peg, with some further technology to enable a message to be sent over the internet and notify the mother (as well as the father) of their daughter's safe arrival to school. This is a simple example of a technology solution that does not already exist in this context, though as researchers and designers aware of research in the area of the internet of things', we are able to infer this by combining a few themes from the list of themes in the thematic frame. The next step would be to design a prototype and evaluate its use with the participants who brought it to our attention, in this case the mother from Family 1.

Based on our use of thematic analysis in an exploratory study investigating family dynamics and the use of technology within families with primary school children, we conclude that as a qualitative method, thematic analysis can be used in $\mathrm{HCl}$ research as a full method (Phase 1-6), when the aim is to present a summary of the data in a form of a high-level thematic map accompanied by the analytic narrative or a partial method (Phase 1-3), when the aim is to use the low-level detail to either improve functionality and usability of the existing technologies or inform the design of new technologies.

Apart from articles outlining pragmatic processes of thematic analysis (Aronson, 1994) or demonstrating the rigour of the method through combining inductive and deductive approach (Fereday, and Muir-Cochrane, 2006), there appeared to be a gap in the literature examining the use of the method itself. The significant contribution of this paper is our investigation into the usefulness of the thematic analysis method when applied within the context of $\mathrm{HCl}$ and exploring in detail the types of findings resulting from each of the six phases.

\section{ACKNOWLEDGEMENTS}

This research is supported by the EPSRC DTA grant. We would especially like to thank all the participating families.

\section{REFERENCES}

Aronson, J. (1994) A pragmatic view of thematic analysis. The Qualitative Report. Volume 2, Number 1, Spring, 1994. Available from: http://www.nova.edu/ssss/QR/Backlssues/QR21/aronson.html [8 August 2013]

Boyatzis, R.E. (1998) Transforming qualitative information: thematic analysis and code development. SAGE Publications, Inc.

Braun, V. and Clarke, V. (2006) Using thematic analysis in psychology. Qualitative Research in Psychology, 3 (2), 77-101.

Brown, N. and Stockman, T. (2011) Supporting the Communication Between Parents and Primary School Children with the Use of Technology. In: Hooper, C.J, Martens J. and Markopoulos, P. Proceedings of the DESIRE'11 Conference: Creativity and Innovation in Design (Doctoral Consortium). Eindhoven, Netherlands, 19-21 October 2011. 423-424

Edwards, J.A. (1993) Principles and contrasting systems of discourse transcription. In Edwards, J.A. and Lampert, M.D., (eds), Talking data: transcription and coding in discourse research. Lawrence Erlbaum Associates, 3-31.

Fereday, J. and Muir-Cochrane, E. (2006) Demonstrating Rigor Using Thematic Analysis: A Hybrid Approach of Inductive and Deductive Coding and Theme Development. International Journal of Qualitative Methods (IJQM), 5(1). 8092.

Güldenpfennig, F., Reitberger, W. and Fitzpatrick, G. (2012) Of Unkempt Hair, Dirty Shirts and Smiling Faces: Capturing Behind the Mobile Camera. Proceedings of NordiCHI'12. Copenhagen, Denmark, 14-17 October 2012. 298-307.

Joffe, H. and Yardley, L. (2004) Content and thematic analysis, In Marks, D.F. and Yardley, L. (eds), Research Methods for Clinical and Health Psychology. London: Sage Publications. 56-67.

Money, A.G. et al. (2008) Older Adults' Experiences of Interacting with Online Forms. Workshop on $\mathrm{HCl}$ and the Older population. Proceedings of the $\mathrm{BCS}-\mathrm{HCl} 2008$, The $22^{\text {nd }}$ 
British HCl Group Annual Conference on People and Computers XXII: Culture, Creativity, Interaction - Volume 2. Liverpool John Moores University, UK, 1-5 September 2008. 27-28.

Pykhtina, O. et al. (2012) Magic Land: The Design and Evaluation of an Interactive Tabletop Supporting Therapeutic Play with Children. Proceedings of the ACM Conference on Designing Interactive Systems (DIS). Newcastle, UK, 11-15 June 2012. 136-145.
Tanaka, A. et al. (2012) Survey and Thematic Analysis Approach as Input to the Design of Mobile Music GUIs. Proceedings of the NIME'12. University of Michigan, Ann Arbour, USA, 21-23 May 2012.

Toth, N. et al. (2012) Teenagers Talking About Energy: Using Narrative Methods to Inform Design. Proceedings of the $\mathrm{CHI}$ '12, Austin, TX, USA, 5-10 May 2012. 2171-2176. 